\title{
Aplikasi Pemrediksi Masa Studi dan Predikat Kelulusan Mahasiswa Informatika Universitas Muhammadiyah Surakarta Menggunakan Metode Naive Bayes
}

\author{
Muh Amin Nurrohmat ${ }^{1 *}$, Yusuf Sulistyo Nugroho ${ }^{1}$ \\ ${ }^{1}$ Program studi Informatika \\ Universitas Muhammadiyah Surakarta \\ Surakarta \\ *Amin.nurrohmat@gmail.com
}

\begin{abstract}
Abstrak
Informatika merupakan salah satu program studi di Universitas Muhammadiyah Surakarta yang memiliki data mahasiswa cukup besar baik data mahasiswa aktif maupun mahasiswa yang sudah lulus. Setiap tahun data tersebut semakin bertambah banyak. Di sisi lain, data yang dimiliki tersebut jika tidak dikelola dengan baik, maka hanya akan menjadi tumpukan data yang tidak bermanfaat, sehingga informasi yang dihasilkan juga tidak banyak. Salah satu cara untuk mengatasi masalah ini adalah data tersebut diubah menjadi sebuah informasi yang bersifat strategis. Oleh karena itu, tujuan penelitian ini adalah membuat suatu aplikasi untuk melakukan prediksi terhadap lama studi dan predikat kelulusan mahasiswa dengan menerapkan teknik data mining. Metode aplikasi yang digunakan dalam data mining untuk prediksi adalah algoritma naïve bayes. Hal ini digunakan untuk menganalisis data, terutama dalam proses pengenalan pola, memprediksi masa studi dan predikat kelulusan. Setelah pengolahan data, aplikasi akan menampilkan laporan serta laporan ringkasan. Hasil penelitian menunjukkan bahwa aplikasi dapat digunakan untuk membantu program studi informatika dalam rangka menemukan informasi strategis terkait dengan lama studi dan predikat kelulusan mahasiswa.
\end{abstract}

\section{PENDAHULUAN}

Dengan perkembangan teknologi informasi yang sangat pesat, informasi menjadi elemen penting dalam perkembangan kehidupan saat ini dan waktu mendatang. Data yang dihasilkan teknologi informasi sangat besar, termasuk bidang pendidikan, ekonomi, industry, dan berbagai bidang lainnya sehingga keperluan akan informasi yang tinggi tetapi tidak diimbangi dengan penyajian informasi yang memadai. Dari data yang jumlahnya sangat besar ini tentu belum digunakan secara optimal, sehingga perlu adanya penggalian ulang dari data yang jumlahnya sangat besar untuk menyajikan informasi yang dibutuhkan.

Dalam dunia pendidikan, data yang berlimpah dan berkesinambungan mengenai siswa yang dibina dan alumni terus dihasilkan. Menurut Jing dan Merceron dalam Ayub[1], data yang berlimpah membuka peluang diterapkannya data mining untuk pengelolaan pendidikan yang lebih baik dan data mining dalam pelaksanaan pembelajaran berbantuan komputer yang lebih efektif. Di sisi lain, Nugroho dan Setyawan[2] menyatakan bahwa Fakultas Komunikasi dan Informatika UMS sejak berdiri pada tahun 2006 telah memiliki sebanyak 2358 mahasiswa termasuk yang sudah lulus sebanyak kurang lebih 600700 mahasiswa. Dengan demikian data-data akademik mahasiswa yang ada juga cukup banyak. Jika data yang melimpah ini hanya dibiarkan menumpuk, maka hanya akan menjadi beban database yang dimiliki. Sementara itu, data-data yang melimpah ini sebenarnya bisa dimanfaatkan sebagai sumber informasi strategis bagi program studi untuk melakukan klasifikasi masa studi lulusan mahasiswa dengan menggunakan teknik data mining. Hal ini tentunya selain dapat memberikan informasi yang bersifat strategis bagi fakultas dan program studi, juga dapat meningkatkan upaya untuk mendorong dan mempercepat kelulusannya. Sehingga selain dapat bermanfaat bagi mahasiswa sendiri, juga dapat meningkatkan nilai akreditasi bagi program studi.

Menurut buku panduan akademik Fakultas Komunikasi dan Informatika Universitas Muhammadiyah Surakarta[4], dalam BAB II disebutkan bahwa "Beban studi mahasiswa program Strata satu (S-1) yang harus ditempuh minimal 144 satuan kredit mahasiswa (SKS) dan maksimal 146 satuan kredit mahasiswa (SKS), dengan batas waktu kurang dari 8 semester dan waktu paling 
lama 14 semester". "Predikat Kelulusan untuk mahasiswa sarjana Strata satu (S-1) yaitu : Memuaskan, Sangat Memuaskan, dan Dengan Pujian (Cumlaude)".

Berdasarkan permasalahan tersebut, dalam penelitian ini akan dibangun sebuah aplikasi untuk membantu program studi dalam memprediksi lama studi dan predikat kelulusan mahasiswa dengan teknik data mining yaitu menggunakan metode Naïve Bayes. Aplikasi tersebut diharapkan dapat digunakan untuk menemukan informasi tentang lama studi dan predikat kelulusan sehingga dapat membantu program studi Informatika dalam mencari solusi dan kebijakan untuk meningkatkan prestasi mahasiswa agar dapat menyelesaikan studinya tepat waktu.

\section{METODE}

\subsection{PENGUMPULAN DATA DAN PENENTUAN ATRIBUT}

Dalam penelitian ini diperlukan data dari seluruh mahasiswa Informatika baik yang sudah lulus maupun yang belum lulus. Semua data diperoleh dari Biro Administrasi Akademik (BAA) dan Laboratorium Fakultas Komunikasi dan Informatika. Data yang digunakan dalam penelitian ini berhubungan dengan data kelulusan dan data akademik mahasiswa.

\subsection{ATRIBUT DATA KELULUSAN}

Data kelulusan yang digunakan sebagai data pelatihan adalah data mahasiswa yang sudah lulus antara angkatan 2007 dan 2010. Atribut yang digunakan dapat dilihat dalam tabel 1.

Tabel 1. Atribut pada Data Kelulusan

\begin{tabular}{|c|c|}
\hline Atribut & Keterangan \\
\hline Jurusan SMA (X1) & $\begin{array}{l}\text { Jurusan yang diambil saat di sekolah } \\
\text { menengah lanjutan }\end{array}$ \\
\hline Gender (X2) & Jenis kelamin mahasiswa \\
\hline Daerah Asal (X3) & Daerah asal mahasiswa \\
\hline Asal Sekolah (X4) & $\begin{array}{l}\text { Daerah asal sekolah menengah } \\
\text { lanjutan }\end{array}$ \\
\hline Asisten (X5) & $\begin{array}{l}\text { Peran mahasiswa sebagai asisten } \\
\text { dalam proses praktikum }\end{array}$ \\
\hline Lama Studi (Y1) & $\begin{array}{l}\text { Masa studi yang dihitung mulai saat } \\
\text { terdaftar sebagai mahasiswa sampai } \\
\text { dinyatakan lulus }\end{array}$ \\
\hline $\begin{array}{l}\text { Predikat Kelulusan } \\
\text { (Y2) }\end{array}$ & $\begin{array}{l}\text { Predikat untuk menyatakan } \\
\text { kemajuan hasil studi mahasiswa } \\
\text { yang dapat dihitung berdasarkan } \\
\text { nilai masing-masing mata kuliah } \\
\text { dikalikan dengan jumlah satuan } \\
\text { kredit semester (SKS) mata kuliah } \\
\text { yang diambil pada periode tertentu } \\
\text { dibagi dengan jumlah seluruh SKS } \\
\text { matakuliah }\end{array}$ \\
\hline
\end{tabular}

\subsection{ATRIBUT DATA MAHASISWA}

Data mahasiswa yang digunakan sebagai data uji adalah data mahasiswa yang masih aktif mengikuti perkuliahan hingga semester genap 2014/2015, dan diambil sampel secara acak. Atribut yang digunakan dapat dilihat dalam tabel 2 .

Tabel 2. Atribut pada Data Mahasiswa

\begin{tabular}{|c|c|}
\hline Atribut & Keterangan \\
\hline Jurusan Asal Sekolah & $\begin{array}{l}\text { Jurusan yang diambil saat duduk di } \\
\text { sekolah menegah lanjutan }\end{array}$ \\
\hline Gender & Jenis kelamin mahasiswa \\
\hline $\begin{array}{l}\text { Daerah Asal } \\
\text { Asal Sekolah }\end{array}$ & $\begin{array}{l}\text { Daerah asal mahasiswa } \\
\text { Daerah asal sekolah menengah } \\
\text { lanjutan }\end{array}$ \\
\hline Asisten Lab & $\begin{array}{l}\text { Peran mahasiswa sebagai asisten } \\
\text { dalam proses praktikum }\end{array}$ \\
\hline
\end{tabular}

\subsection{PENENTUAN NILAI CLASS DATA}

Nilai class data penelitian yang telah dikumpulkan kemudian diubah menyesuaikan kebutuhan data mining. Tabel 3 menunjukkan nilai class masing-masing atribut yang digunakan.

Nilai class pada atribut Lama Studi dikategorikan berdasarkan semester yang ditempuh pada saat lulus, yaitu :

1) Tepat waktu, jika lama studi 8 semester atau kurang dari 8 semester.

2) Terlambat, jika lama studi lebih dari 8 semester.

Sedangkan nilai class pada atribut Predikat Kelulusan ditentukan berdasarkan IPK yang dibagi menjadi tiga, yaitu :

1) Memuaskan, jika IPK antara 2,00 dan 2,75

2) Sangat Memuaskan, jika IPK antara 2,76 dan 3,50

3) Cumlaude, jika IPK antara 3,51 dan 4,00

Tabel 3. Atribut dan Nilai Class dalam Data

\begin{tabular}{|c|c|c|}
\hline Atribut & \multicolumn{2}{|c|}{ Class dalam Data } \\
\hline Jurusan SMA & IPA, IPS dan Lain & \\
\hline Gender & Pria dan Wanita & \\
\hline Daerah asal & WIB, WITA, dan WIT & \\
\hline Asal sekolah & WIB, WITA, dan WIT & \\
\hline Asisten Lab & Ya dan Tidak & \\
\hline Lama studi & Tepat dan Terlambat & \\
\hline Predikat Kelulusan & $\begin{array}{l}\text { Cumlaude, Sangat } \\
\text { Memuaskan }\end{array}$ & Memuaskan, \\
\hline
\end{tabular}

\subsection{ANALISIS DATA}

Tahap analisis data dilakukan perhitungan menggunakan algoritma Nä̈ve Bayes. Algoritma naive bayes merupakan pengklasifikasian dengan metode probabilitas dan statistic untuk memprediksi peluang di masa depan[4]. Adapun algoritma ini dapat dihitung menggunakan persamaan 1 .

$P(H \mid X)=\frac{\mathrm{P}(\mathrm{X} \mid \mathrm{H}) \cdot \mathrm{P}(\mathrm{H})}{P(X)}$

\subsection{PERANCANGAN USE CASE DIAGRAM}

Aplikasi yang dibangun memiliki tujuan untuk melakukan analisis data mahasiswa terkait dengan 
kelulusannya. Perancangan aplikasi dimulai dari tahap pembuatan use case diagram seperti yang ditunjukkan pada gambar 1 dan tabel 4.

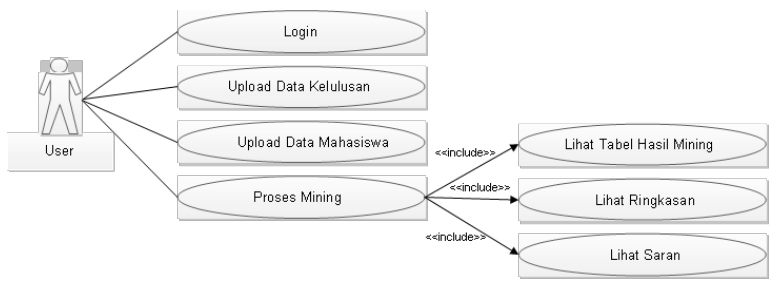

Gambar 1. Use Case Diagram dengan User sebagai Aktor

Tabel 4. Keterangan use case diagram

\begin{tabular}{|c|c|c|}
\hline Nama Use Case & Aktor & Deskripsi \\
\hline Login & User & $\begin{array}{l}\text { Menggambarkan kegiatan } \\
\text { input username dan } \\
\text { password }\end{array}$ \\
\hline Ambil data training & User & $\begin{array}{l}\text { Menggambarkan kegiatan } \\
\text { mengambil data kelulusan }\end{array}$ \\
\hline Ambil data testing & User & $\begin{array}{l}\text { Menggambarkan kegiatan } \\
\text { mengambil data mahasiswa } \\
\text { aktif }\end{array}$ \\
\hline Proses Mining & User & $\begin{array}{l}\text { Menggambarkan kegiatan } \\
\text { proses mining atribut lama } \\
\text { studi dan IPK }\end{array}$ \\
\hline $\begin{array}{l}\text { Laporan hasil } \\
\text { Mining }\end{array}$ & User & $\begin{array}{l}\text { Menggambarkan kegiatan } \\
\text { menampilkan hasil mining }\end{array}$ \\
\hline $\begin{array}{l}\mathrm{L} \text { a } \mathrm{p} \text { o } \mathrm{r} \text { a } \mathrm{n} \\
\text { Rangkuman }\end{array}$ & User & $\begin{array}{l}\text { Menggambarkan kegiatan } \\
\text { menampilkan rangkuman } \\
\text { dari proses mining }\end{array}$ \\
\hline Laporan saran & User & $\begin{array}{l}\text { Menggambarkan kegiatan } \\
\text { melihat saran yang } \\
\text { diberikan untuk prodi }\end{array}$ \\
\hline
\end{tabular}

\section{HASIL}

Hasil dari penelitian ini adalah sebuah aplikasi data mining untuk memprediksi lama studi dan predikat kelulusan mahasiswa program studi Informatika menggunakan metode Naïve Bayes. Aplikasi ini memiliki form-form yang bisa diakses oleh user untuk melakukan prediksi, antara lain:

\subsection{FORM UTAMA}

Form utama akan muncul jika user sukses melakukan login. Form yang ditunjukkan seperti gambar 2 ini berfungsi untuk mengakses menu-menu yang terdapat dalam aplikasi antara lain Menu File Data yang berisi submenu Upload data training, Upload data testing, Exit, Menu Report dan Menu Help berisi sub menu Petunjuk dan About.

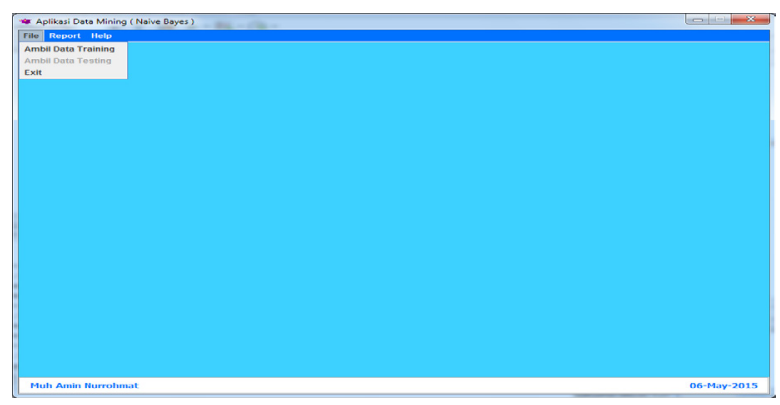

Gambar 2. Form Utama Aplikasi Prediksi Masa Studi dan Predikat Kelulusan

\subsection{FORM UPLOAD DATA TRAINING}

Form Upload Data Training yang ditunjukkan pada gambar 3 akan ditampilkan setelah user memilih submenu Upload Data Training pada Menu File. User dapat mengambil data kelulusan kemudian menyimpannya dalam tabel. Jika berhasil, user dapat melanjutkan proses mining dan dilanjutkan ke form Upload Data Testing.

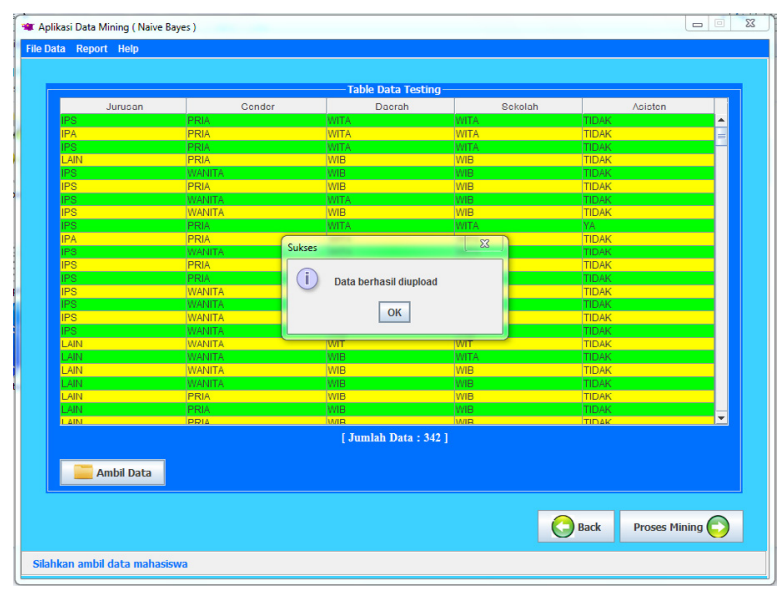

Gambar 3. Form Upload Data Training

\subsection{FORM HASIL MINING}

Form Upload Data Testing akan ditampilkan setelah user mengambil data kelulusan pada form Upload Data Training. Data training dan data testing siap diproses mining menggunakan algoritma Naïve Bayes dan hasil proses mining tersebut akan muncul pada form Hasil Mining seperti ya ng ditunjukkan pada gambar 4 dan bisa dilihat dalam bentuk grafik seperti pada gambar 5 . 


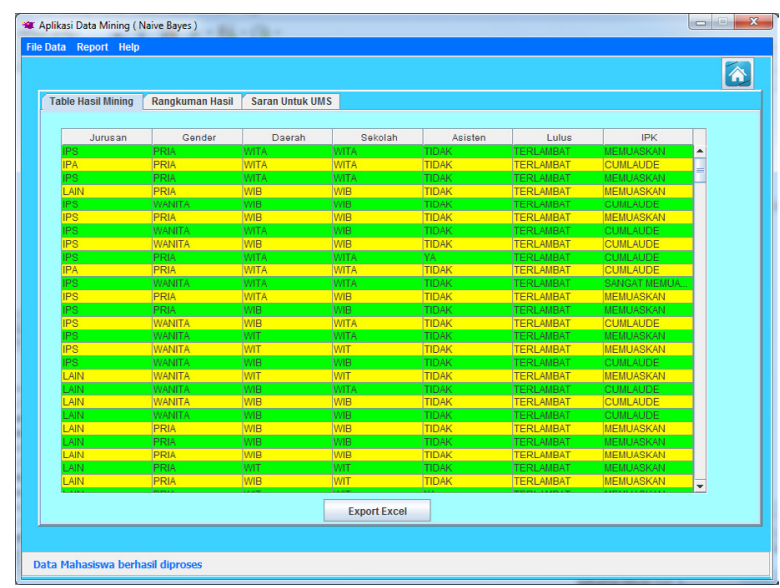

Gambar 4. Form Hasil Mining

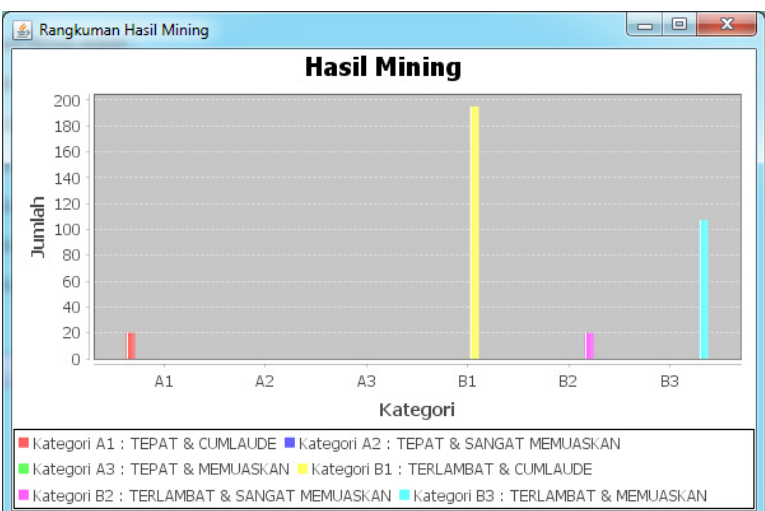

\section{DISKUSI}

Algoritma Naïve Bayes digunakan untuk melakukan perhitungan terhadap probabilitas nilai class data dalam data testing untuk setiap variabel dependen $(\mathrm{Y})$ berdasarkan data training. Data mahasiswa yang telah lulus diatur sebagai data training dan data mahasiswa aktif sebagai data testing yang dipilih secara acak. Tabel 5 adalah contoh potongan data training yang diambil secara random, sedangkan tabel 6 merupakan contoh data testing yang digunakan sebagai hipotesis.

Untuk mencari nilai class variabel Lama Studi, diperlukan perhitungan probabilitas prior terhadap data training, dengan tahapan sebagai berikut:

\subsection{MENGHITUNG PROBABILITAS PRIOR MASING-MASING CLASS VARIABEL LAMA \\ STUDI (Y1).}

Pada tahap ini dilakukan perhitungan, persamaan (2) dan (3), untuk mencari nilai probabilitas masing-masing class yaitu "Tepat" dan "Terlambat" pada variabel Y1.

$P(Y 1=$ Tepat $)=\frac{\text { Jumlah class "Tepat" }}{\text { Jumlah data }}=\frac{4}{10}$

Gambar 5. Grafik Hasil Mining

Tabel 5. Potongan Data Training

\begin{tabular}{|c|c|c|c|c|c|c|}
\hline $\begin{array}{c}\text { Jurusan } \\
\text { SMA }\end{array}$ & Gender & $\begin{array}{c}\text { Daerah } \\
\text { Asal }\end{array}$ & $\begin{array}{c}\text { Asal } \\
\text { Sekolah }\end{array}$ & Asisten & Lama Studi & $\begin{array}{l}\text { Predikat } \\
\text { Kelulusan } \\
\text { (IPK) }\end{array}$ \\
\hline IPA & Pria & WIB & WIB & Ya & Tepat & Cumlaude \\
\hline IPS & Wanita & WIB & WIB & Ya & Tepat & Cumlaude \\
\hline IPA & Pria & WIB & WIB & $\mathrm{Ya}$ & Tepat & $\begin{array}{l}\mathrm{S} \text { a } \mathrm{n} \quad \mathrm{g} \text { a } \mathrm{t} \\
\text { Memuaskan }\end{array}$ \\
\hline IPS & Pria & WIT & WIT & $\mathrm{Ya}$ & Terlambat & Memuaskan \\
\hline IPA & Pria & WITA & WITA & Ya & Terlambat & Memuaskan \\
\hline IPA & Pria & WIB & WIB & Tidak & Tepat & Cumlaude \\
\hline IPS & Pria & WITA & WIB & Tidak & Terlambat & Memuaskan \\
\hline IPS & Wanita & WIB & WIB & Tidak & Terlambat & $\begin{array}{l}\mathrm{S} \text { a } \mathrm{n} \quad \mathrm{g} \text { a } \\
\text { Memuaskan }\end{array}$ \\
\hline IPA & Pria & WITA & WITA & Ya & Terlambat & Memuaskan \\
\hline Lain & Pria & WITA & WITA & $\mathrm{Ya}$ & Terlambat & Memuaskan \\
\hline
\end{tabular}


Tabel 6. Contoh Data Testing

\begin{tabular}{ccccccc}
\hline Jurusan SMA & Gender & Daerah Asal & Asal Sekolah & Asisten & Lama Studi & IPK \\
\hline IPA & Pria & WIB & WIB & Ya & ? \\
\hline
\end{tabular}

$P(Y 1=$ Terlambat $)=\frac{\text { Jumlah class "Terlambat" }}{\text { Jumlah data }}=\frac{6}{10}$

\subsection{MENGHITUNG PROBABILITAS BER- SYARAT SESUAI NILAI CLASS YANG DIAJUKAN DALAM DATA TESTING.}

Pada tahap ini dilakukan perhitungan, persamaan (4)-(8), untuk mencari nilai probabilitas bersyarat masingmasing class dalam variabel $\mathrm{X}$ terhadap variabel $\mathrm{Y} 1$.

$$
\begin{aligned}
& P(X 1=I P A \mid Y 1=\text { Tepat })=\frac{3}{4} ; P(X 1=I P A \mid Y 1=\text { Terlambat })=\frac{2}{6} \\
& P(X 2=\text { Pria } \mid Y 1=\text { Tepat })=\frac{3}{4} ; P(X 2=\text { Pria } \mid Y 1=\text { Terlambat })=\frac{5}{6} \\
& P(X 3=\text { WIB } \mid Y 1=\text { Tepat })=\frac{4}{4} ; P(X 3=\text { WIB } \mid Y 1=\text { Terlambat })=\frac{1}{6} \\
& P(X 4=\text { WIB } \mid Y 1=\text { Tepat })=\frac{4}{4} ; P(X 4=\text { WIB } \mid Y 1=\text { Terlambat })=\frac{2}{6} \\
& P\left(X 5=Y_{a} \mid Y 1=\text { Tepat }\right)=\frac{3}{4} ; P\left(X 5=Y_{a} \mid Y 1=\text { Terlambat }\right)=\frac{3}{6}
\end{aligned}
$$

\subsection{PERHITUNGAN NAÏVE BAYES.}

Algoritma naïve bayes digunakan untuk mencari nilai confidence atau peluang terjadinya masing-masing class variabel $\mathrm{Y} 1$ berdasarkan variabel $\mathrm{X}$ yang diajukan, persamaan (9) dan (10), Nilai confidence masing-masing class tersebut kemudian dibandingkan untuk mengetahui peluang yang lebih besar untuk memprediksi nilai class yang muncul pada variabel Y1.

a) Nilai confidence pada variabel Y1 untuk class $=$ 'Tepat'

$P(X 1=I P A, X 2=$ Pria $, X 3=W l B, X 4=W l B, X 5=Y a \mid Y 1=$ Tepat $)$

$$
=\frac{3}{4} \cdot \frac{3}{4} \cdot \frac{4}{4} \cdot \frac{4}{4} \cdot \frac{3}{4} \cdot \frac{4}{10}=0,168
$$

b) Nilai confidence pada variabel Y1 untuk class $=$ Terlambat'

$P(X 1=I P A, X 2=$ Pria $, X 3=W I B, X 4=W I B, X 5=Y a \mid Y 1=$ Terlambat $)$

$$
=\frac{2}{6} \cdot \frac{5}{6} \cdot \frac{1}{6} \cdot \frac{2}{6} \cdot \frac{3}{6} \cdot \frac{6}{10}=0,00432
$$

Berdasarkan nilai confidence masing-masing class pada variabel Y1 dapat dilihat bahwa nilai confidence untuk class = 'Tepat' lebih besar daripada nilai confidence pada class $=$ 'Terlambat'. Dengan demikian, prediksi class variabel Y1 pada data testing adalah "Tepat".

Sedangkan untuk mencari nilai class variabel Predikat Kelulusan, diperlukan perhitungan probabilitas prior terhadap data training, dengan tahapan sebagai berikut:

\subsection{MENGHITUNG PROBABILITAS PRIOR MASING-MASING CLASS VARIABEL PREDIKAT KELULUSAN (Y2).}

Pada tahap ini dilakukan perhitungan, persamaan (11)-(13), untuk mencari nilai probabilitas masingmasing class yaitu "Cumlaude", "Sangat Memuaskan" dan "Memuaskan" pada variabel Y2.

$P(Y 2=$ Cumlaude $)=\frac{\text { Jumlah class "Cumlaude" }}{\text { Jumlah data }}=\frac{3}{10}$

$P(Y 2=$ Sangat Memuaskan $)=\frac{\text { Jumlah class "Sangat Memuaskan" }}{\text { Jumlah data }}=\frac{2}{10}$

$P(Y 2=$ Memuaskan $)=\frac{\text { Jumlah class "Memuaskan" }}{\text { Jumlah data }}=\frac{5}{10}$

\subsection{MENGHITUNG PROBABILITAS BER- SYARAT SESUAI NILAI CLASS YANG DIAJUKAN DALAM DATA TESTING.}

Pada tahap ini dilakukan perhitungan, persamaan (14)(21), untuk mencari nilai probabilitas bersyarat masingmasing class dalam variabel $\mathrm{X}$ terhadap variabel Y2.

$P(X 1=I P A \mid Y 2=$ Cumlaude $)=\frac{2}{3} ; P(X 1=I P A \mid Y 2=$ Sangat Memuaskan $)=\frac{1}{2}$

$P(X 1=I P A \mid Y 2=$ Memuaskan $)=\frac{2}{5} ; P\left(X 2=P\right.$ ria $\mid Y_{2}=$ (umlaude $)=\frac{2}{3}$

$P(X 2=P$ ria $\mid Y 2=$ Sangat Memuaskan $)=\frac{1}{2} ; P(X 2=$ Pria $\mid Y 2=$ Memuaskan $)=\frac{5}{5}$

$P(X 3=W I B \mid Y 2=$ Cumlaude $)=\frac{3}{3} ; P(X 3=W I B \mid Y 2=$ Sangat Memuaskan $)=\frac{2}{2}$

$P(X 3=W I B \mid Y 2=$ Memuaskan $)=\frac{0}{5} ; P(X 4=W I B \mid Y 2=$ (umlaude $)=\frac{3}{3}$

$P(X 4=W I B \mid Y 2=$ Sangat Memuaskan $)=\frac{2}{2} ; P(X 4=W I B \mid Y 2=$ Memuaskan $)=\frac{1}{5}$

$P\left(X 5=Y_{a} \mid Y_{2}=\right.$ Cumlaude $)=\frac{2}{3} ; P\left(X 5=Y_{a} \mid Y_{2}=\right.$ Sangat Memuaskan $)=\frac{1}{2}$

$P\left(X 5=Y_{Q} \mid Y 2=\right.$ Memuaskan $)=\frac{4}{5}$

\subsection{PERHITUNGAN NAÏVE BAYES.}

Nilai confidence masing-masing class dalam variabel Y2, persamaan (22)-(24), kemudian dibandingkan untuk mengetahui peluang yang lebih besar untuk memprediksi nilai class yang muncul pada variabel $\mathrm{Y} 2$ tersebut.

a) Nilai confidence pada variabel Y2 untuk class $=$ 'Cumlaude'

$P\left(X 1=I P A, X 2=\right.$ Pria $, X 3=W I B, X 4=W I B, X 5=Y_{a} \mid Y 2=($ umlaude $)$ 


$$
=\frac{2}{3} \cdot \frac{2}{3} \cdot \frac{3}{3} \cdot \frac{3}{3} \cdot \frac{2}{3} \cdot \frac{3}{10}=0,097746
$$

b) Nilai confidence pada variabel Y2 untuk class = 'Sangat Memuaskan'

$P\left(X 1=I P A, X 2=P\right.$ ria $, X 3=W I B, X 4=W I B, X 5=Y_{a} \mid Y 2=$ Sangat Memuaskan $)$

$$
=\frac{1}{2} \cdot \frac{1}{2} \cdot \frac{2}{2} \cdot \frac{2}{2} \cdot \frac{1}{2} \cdot \frac{2}{10}=0,025
$$

c) Nilai confidence pada variabel $\mathrm{Y} 2$ untuk class $=$ 'Memuaskan'

$P\left(X 1=I P A, X 2=P\right.$ ria $, X 3=W I B, X 4=W I B, X 5=Y_{a} \mid Y 2=$ Memuaskan $)$

$$
=\frac{2}{5} \cdot \frac{5}{5} \cdot \frac{0}{5} \cdot \frac{1}{5} \cdot \frac{4}{5} \cdot \frac{5}{10}=0
$$

Berdasarkan nilai confidence masing-masing class pada variabel Y2 dapat dilihat bahwa nilai confidence untuk class = 'Cumlaude' lebih besar daripada nilai confidence pada class $=$ 'Sangat Memuaskan' dan class $=$ 'Memuaskan'. Dengan demikian, prediksi class variabel Y2 pada data testing adalah "Cumlaude".

\section{KESIMPULAN}

Berdasarkan hasil penelitian yang dilakukan maka dapat disimpulkan bahwa aplikasi Data Mining ini dapat digunakan untuk menampilkan informasi hasil prediksi lama studi dan predikat kelulusan dalam bentuk tabel dengan menggunakan data mahasiswa yang telah lulus sebagai data training dan data mahasiswa yang masih aktif sebagai data testing. Variabel bebas $(\mathrm{X})$ yang terdiri dari jurusan asal sekolah, gender, daerah asal, asal sekolah, dan asisten dapat digunakan sebagai variabel untuk memprediksi lama studi dan predikat kelulusan mahasiswa.

Algoritma naïve bayes dapat digunakan untuk memprediksi suatu nilai class variabel dalam data testing berdasarkan perbandingan nilai probabilitas masingmasing class variabel pada data training terhadap variabel X yang diajukan dalam data testing.

\section{DAFTAR PUSTAKA}

[1] Ayub, Mewati, "Proses Data Mining dalam Sistem Pembelajaran Berbantuan Komputer", Jurnal Sistem Informasi Vol. 2 No. 1 Maret 2007 : 21-30

[2] Nugroho, Yusuf Sulistyo, dan Setyawan., "Klasifikasi Masa Studi Mahasiswa Fakultas Komunikasi dan Informatika", Jurnal Komunikasi dan Teknologi Informasi (KomuniTi), Volume VI No. I Maret 2014.

[3] UMS, "Panduan Akademik Fakultas Komunikasi dan Informatika UMS 2014/2015", Universitas Muhammadiyah Surakarta., Surakarta, 2014

[4] Bustami, "Penerapan Algoritma Naive Bayes untuk Mengklasifikasi Data Nasabah Asuransi”,. Jurnal Penelitian Teknik Informatika, 2013 